\title{
KESELARASAN PENGGUNAAN LAHAN DENGAN POLA RUANG DAN ARAHAN PENGEMBANGAN RUANG TERBUKA HIJAU DI KABUPATEN BENGKULU SELATAN
}

\section{Conformity of Land Use with Spatial Pattern and Direction of Green Open Space Development in South Bengkulu Regency}

\author{
Santun R.P. Sitorus'1)*, Engge Mustamei2) dan Setyardi P. Mulya1) \\ 1) Departemen Ilmu Tanah dan Sumberdaya Lahan, Fakultas Pertanian, IPB University, Jl. Meranti \\ Kampus IPB Dramaga, Bogor 16680 \\ 2) Program Studi Manajemen Sumberdaya Lahan, Departemen Ilmu Tanah dan Sumberdaya Lahan, \\ Fakultas Pertanian IPB University, Jl. Meranti Kampus IPB Dramaga, Bogor 16680
}

\begin{abstract}
Bengkulu Selatan Regency is a region that continues to grow, as evidenced by the submission of Manna to become a city. Land use must always be evaluated by referring to the regional spatial plan (RTRW). In accordance with the Spatial Planning Law No. 26 of 2007, one must be at least green open space (RTH) (30\%) consisting of public green space (20\%) and private green space (10\%). This study aims to identify existing land use (2018), to evaluate land use confirmity with the spatial plan, to know the type and extent of GOS spreading (Kota Manna), to prepare the direction of GOS development plan. The method used is the analysis of geographic information systems, logical alignment matrices, and descriptive. The results showed that the three largest existing land uses were 55,861.0 ha of forest (47.91\%), 43,186.7 ha of plantation (37.04), and 7,257.8 ha of rice fields (6.23\%). The area of land use that is in conformed with the spatial pattern of RTRW is $84,823.7$ ha $(73 \%)$, transition is 27,115.0 ha (23\%), and is not conformed at 4,648.0 ha (4\%). Appropriate land use is recommended to continue and not conformed land use is advisable to be stopped for further development. The existing public GOS is still less (-23.2 ha) based on the size of the area, but it has exceeded the needs based on the population (2,515.3 ha). The development of public green space can be done on the first priority land with an area of 38.6 ha because it is sufficient for the needs of public GOS based on an area, directives for control of spatial use are carried out with four instruments, namely zoning regulations must be immediately made to establish space allocation zones, licensing must be more tightened in accordance with the direction of space allocation, carry out control of providing incentives and disincentives, by making operational guidelines in its implementation, and applying sanctions to every violator to cause a deterrent effect.
\end{abstract}

Keywords: Conformity, land use, private GOS, public GOS, RTRW

\begin{abstract}
ABSTRAK
Kabupaten Bengkulu Selatan merupakan wilayah yang terus berkembang, terbukti dengan sedang dilakukannya pengajuan Manna sebagai ibukota Kabupaten menjadi sebuah kota. Pemanfaatan lahan harus selalu dievaluasi dengan berpedoman pada rencana tata ruang wilayah (RTRW). Sesuai UU Penataan Ruang No 26 Tahun 2007, salah satunya harus memenuhi kebutuhan minimal ruang terbuka hijau (RTH) (30\%) yang terdiri dari RTH publik (20\%) dan RTH privat (10\%). Penelitian ini bertujuan mengidentifikasi penggunaan lahan eksisting Kabupaten Bengkulu Selatan tahun 2018, mengevaluasi keselarasan penggunaan lahan dengan rencana pola ruang RTRW, mengetahui jenis dan luas penyebaran RTH di Kota Manna tahun 2018, dan menyusun arahan rencana pengembangan RTH. Metode yang digunakan adalah analisis sistem informasi geografi, matriks logis keselarasan dan deskriptif. Hasil penelitian menunjukkan ada 3 penggunaan lahan eksisting terluas adalah hutan seluas 55,861.0 ha (47.91\%), perkebunan 43,186.7 ha (37.04), dan sawah 7,257.8 ha (6.23\%). Luas penggunaan lahan yang selaras dengan pola ruang RTRW adalah sebesar 84,823.7 ha (73\%), transisi sebesar 27,115.0 ha (23\%), dan tidak selaras sebesar 4.648.0 ha (4\%). Penggunaan lahan yang selaras disarankan untuk dilanjutkan dan yang tidak selaras disarankan pengembangan lebih lanjut untuk dihentikan. Luas RTH publik eksisting Kota Manna masih kurang 23.2 ha berdasarkan luas wilayah, tetapi sudah melebihi kebutuhan berdasarkan jumlah penduduk 2,515.3 ha. Pengembangan ruang hijau publik dapat dilakukan pada lahan prioritas pertama dengan luas 38,6 ha karena cukup untuk kebutuhan RTH publik, arahan untuk pengendalian penggunaan ruang dilakukan dengan empat instrumen, yaitu peraturan zonasi harus segera dibuat untuk menetapkan zona alokasi ruang, perizinan harus lebih diperketat sesuai dengan arah alokasi ruang, melaksanakan kontrol pemberian insentif dan disinsentif dengan membuat pedoman operasional dalam implementasinya, dan menerapkan sanksi kepada setiap pelanggar untuk menyebabkan efek jera.
\end{abstract}

Kata kunci: Keselarasan, penggunaan lahan, RTH privat, RTH publik, RTRW 


\section{PENDAHULUAN}

Kabupaten Bengkulu Selatan merupakan wilayah yang terus berkembang. Tahun 2016, Pendapatan Asli Daerah (PAD) meningkat sebesar $23.61 \%$ dibandingkan tahun 2015, dan pada tahun 2015 meningkat $19.76 \%$ dibandingkan tahun 2014 (BPS, 2017). Hal tersebut merangsang pertumbuhan penduduk dan pusat-pusat pertumbuhan baru dengan cepat, sehingga mendorong terjadinya perubahan penggunaan lahan, kepemilikan lahan, serta munculnya usaha-usaha baru di bidang perekonomian. Pusat pertumbuhan baru pada wilayah yang berkembang berkorelasi kuat dengan semakin banyaknya jumlah sarana pelayanan dan jumlah jenis sarana di suatu wilayah (Rustiadi et al., 2011).

Pengembangan wilayah Kabupaten Bengkulu Selatan dengan Kota Manna sebagai ibukota perlu berwawasan lingkungan (green city) sesuai dengan Undang-undang (UU) Penataan Ruang No 26 Tahun 2007. Ruang terbuka hijau (RTH) merupakan salah satu atribut kota berwawasan lingkungan. Kecukupan RTH untuk kawasan perkotaan dapat dihitung berdasarkan luas wilayah, jumlah penduduk, serta kebutuhan untuk fungsi tertentu seperti kenyamanan, kecukupan air atau kecukupan oksigen. Berdasarkan kepemilikannya, RTH terdiri dari RTH publik dan RTH privat. Proporsi dari RTH tersebut adalah minimal sebesar 30\% dari luas wilayah terdiri dari $20 \%$ RTH publik dan 10\% RTH privat. Penyediaan RTH di Kawasan Perkotaan mengacu pada standar minimal kebutuhan RTH per penduduk seluas $20 \mathrm{~m}^{2}$ (Kementerian PU 2008), sedangkan menurut rekomendasi World Health Organisation (WHO) adalah $9.5 \mathrm{~m}^{2} /$ penduduk (Senanayake et al., 2013).

Di berbagai wilayah perkotaan, luas RTH cenderung mengalami penurunan dan perubahan lahan RTH tersebut dipengaruhi oleh alih fungsi lahan RTH (Sitorus et al., 2013). Faktor yang mempengaruhi perubahan lahan RTH di berbagai kota cukup beragam. Hasil penelitian Sitorus et al. (2012) di Jakarta Timur menunjukkan faktor yang mempengaruhi perubahan lahan RTH adalah alokasi RTH dalam RTRW, fasilitas kesehatan, jumlah pendatang, kepadatan penduduk dan fasilitas pendidikan. Sementara itu di Bekasi menyebutkan faktor yang mempengaruhi perubahan lahan RTH adalah jarak ke pusat kota, luas RTH awal, perubahan lahan terbangun, jarak terhadap fasilitas sosial, jarak terhadap fasilitas pendidikan dan perubahan terhadap fasilitas ekonomi. Hasil penelitian Suwarli et al. (2012) juga di Bekasi, faktor utama yang mempengaruhi perubahan lahan RTH adalah jumlah penduduk. Selain itu, variabel lain yang berpengaruh adalah jumlah sarana pendidikan, jumlah pasar, jumlah supermarket, jumlah pemukiman, jumlah industri, jumlah restoran dan jumlah hotel. Menurut Putri dan Zain (2010) menunjukkan bahwa faktor aksesibilitas merupakan hal krusial yang mendorong perubahan RTH dan perkembangan Kota Bandung.

Berbagai cara dapat dilakukan untuk menghitung kebutuhan luas RTH yaitu berdasarkan luas wilayah, jumlah penduduk, indeks kenyamanan, kebutuhan oksigen. Berdasarkan prediksi jumlah penduduk tahun 2035 kebutuhan RTH adalah seluas 1,197.1 ha. Selain itu, kebutuhan RTH juga dapat dihitung berdasarkan indeks kenyamanan. Kebutuhan RTH juga bisa diperhitungkan berdasarkan kebutuhan oksigen. Hasil penelitian Putra (2012) di Kota Manado menunjukkan bahwa kebutuhan oksigen sebesar $445.603 \mathrm{~kg} /$ hari sehingga RTH yang dibutuhkan adalah seluas 892 ha.

Untuk mengetahui kelayakan suatu wilayah mendapat prioritas untuk penyediaan RTH dapat dilakukan dengan pendekatan jumlah penduduk (Senanayake et al. 2013). Wilayah dengan kepadatan tinggi dan memiliki nilai luas minimum RTH per kapita rendah termasuk dalam wilayah yang perlu penyediaan RTH. Rijal (2008) dalam penelitiannya melakukan analisis kebutuhan RTH berdasarkan pendekatan ekologis dan jumlah penduduk, dimana kebutuhan berdasarkan jumlah penduduk jauh lebih tinggi dibandingkan pendekatan ekologis.

Perencanaan tata ruang kabupaten/kota dipersiapkan untuk mengantisipasi perkembangan kabupaten/kotayang pesat. Perkembangan pemanfaatan ruang Kabupaten Bengkulu Selatan menuntut ketelitian dan kearifan dalam pengaturan pemanfaatan ruang dan pengendaliannya. Manna sebagai ibukota Kabupaten Bengkulu Selatan saat ini belum mengakomodasikan pembangunan berbasis pada atribut kota hijau. RTH sebagai salah satu atribut penting untuk tercapainya kota hijau masih belum menjadi prioritas dalam arahan pembangunan (Sitorus et al., 2013). Luas RTH publik di Kota Manna merupakan persoalan yang perlu diakomodasi oleh pemerintah kabupaten, sehingga sesuai dengan ketersediaan dan kecukupan RTH. Saat ini Kota Manna belum memiliki informasi dan data RTH yang lengkap baik dan akurat, terutama data sebaran RTH secara spasial.

Adapun tujuan penelitian ini adalah: (i) Mengidentifikasi penggunaan lahan eksisting Kabupaten Bengkulu Selatan tahun 2018, (ii) Mengevaluasi keselarasan penggunaan lahan eksisting terhadap rencana pola ruang RTRW Kabupaten Bengkulu Selatan, (iii) Mengetahui jenis, luasdan penyebaraan RTH di Kota Manna, Kabupaten Bengkulu Selatan, (iv) Menyusun arahan rencana pengembangan RTH untuk memenuhi luas RTH di Kota Manna, Kabupaten Bengkulu Selatan, (v) Menyusun arahan pengendalian pemanfaatan ruang Kabupaten Bengkulu Selatan.

\section{BAHAN DAN METODE}

Penelitan dilaksanakan di Kabupaten Bengkulu Selatan (Gambar 1). Penelitian dilaksanakan selama 7 bulan mulai bulan November 2017 sampai dengan Mei 2018. Tabulasi dan analisis data dilakukan di Studio Perencanaan Pengembangan Wilayah, Departemen Ilmu Tanah dan Sumberdaya Lahan, Fakultas Pertanian, Institut Pertanian Bogor.

\section{Jenis Data, Sumber Data, Bahan dan Alat Penelitian}

Jenis data yang digunakan dalam penelitian ini adalah data primer dan sekunder. Data primer berupa jenis penggunaan lahan dan RTH diperoleh dari pengumpulan data di lapang dengan melakukan interpretasi citra,pengecekan lapang, dan wawancara lapang untuk mengetahui keselarasan penggunaan lahan dengan pola ruang di Kabupaten Bengkulu Selatan dan jenis penyebaran serta luas RTH di Kota Manna. Data sekunder diperoleh 
dari instansi-instansi di Kabupaten Bengkulu Selatan dan internet. Data sekunder berupa citra Google Earth 2017 dari internet sedangkan peta dan dokumen RTRW, peta administrasi, peta jalan, dan lain-lain diperoleh dari BAPPEDA Penelitian Pengembangan Kabupaten Bengkulu Selatan. Bahan yang digunakan pada penelitian ini adalah peta batas administrasi, citra google earth, peta jalan, dan peta RTRW Kabupaten Bengkulu Selatan. Peralatan yang digunakan yaitu komputer dengan perangkat lunak berupa software ArcGIS 10.3, Google Earth Pro, Avenza Maps, Statistica 7.0, Microsoft Office, SAS Planet, Microsoft Excel, Global Positioning System (GPS), kuesioner dan kamera untuk pengamatan lapang.

\section{Teknik Pengumpulan Data dan Analisis Data}

Pengumpulan data primer diperoleh dari pengecekan lapang dan wawancara dengan menggunakan kuesioner. Data sekunder diperoleh dari berbagai lembaga atau instansi terkait, perpustakaan dan internet. Pengambilan data primer berupa pengecekan lapang dilakukan pada tiga titik sampel yang berbeda pada setiap jenis penggunaan lahan. Hasil pengecekan lapang digunakan untuk memverifikasi dan memperbaharui peta penggunaan lahan sesuai dengan kondisi eksisting. Jenis penggunaan lahan yang digunakan sebanyak 8 jenis, yaitu pemukiman, tegalan, tubuh air, sawah, hutan, industri, perkebunan, dan lahan terbuka atau semak belukar. Wawancara dilakukan pada responden dari masyarakat/aparat, instansi terkait seperti Bappeda Litbang, BPN, DLHK, Pemda, dan Dinas PUPR Kabupaten Bengkulu Selatan untuk mendapatkan gambaran umum penggunaan lahan dan pemanfaatan ruang di Kabupaten Bengkulu Selatan. Penetapan responden untuk wawancara lapang menggunakan teknik sampling non-probabilitas melalui pendekatan purposive sampling, dimana responden ditentukan berdasarkan pertimbangan persentase luas penggunaan lahan eksisting yang tidak selaras dengan rencana pola ruang.

Teknik analisis data yang digunakan untuk masing-masing tujuan penelitian adalah sebagai berikut:

1. Mengidentifikasi penggunaan lahan eksisting

Interpretasi citra dilakukan untuk menentukan bentuk dan sifat obyek yang tampak pada citra dan deskripsinya. Interpretasi citra untuk penggunaan lahan di wilayah studi dilakukan secara visual citra google earth melalui digitasi on screen dengan menggunakan aplikasi ArcGIS 10.3. Skala digitasi yang digunakan dalam interpretasi citra adalah 1:10.000.

2. Mengevaluasi keselarasan penggunaan lahan dengan rencana pola ruang Kabupaten Bengkulu Selatan.

Peta penggunaan lahan eksisting tahun 2018 ditumpangtindihkan (overlay) dengan peta pola ruang RTRW Kabupaten Bengkulu Selatan tahun 2011-2031. Hasil overlay di-query berdasarkan matrik logika keselarasan penggunaan lahan dengan pola ruang.

3. Mengetahui jenis dan luas RTH Kota Manna

Kebutuhan RTH berdasarkan jumlah penduduk dilakukan dengan mengalikan jumlah penduduk dengan standar luas RTH per penduduk. Kebutuhan RTH per penduduk sesuai dengan Permen PU No. 05 Tahun 2008 adalah $20 \mathrm{~m}^{2} /$ penduduk. Persamaan (i) digunakan untuk menentukan luas RTH berdasarkan jumlah penduduk.

\section{$R T H=P i x k\left(m^{2} / o r a n g\right)$}

(i)

Keterangan:

Pi: Jumlah penduduk pada wilayah i, k: Nilai ketentuan luas RTH per penduduk berdasarkan Peraturan Menteri PU No. 05/PRT/M/2008.

4. Menyusun arahan rencana pengembangan untuk memenuhi luas ruang terbuka hijau di Kota Manna, Kabupaten Bengkulu Selatan.

a. Pendugaan Pertumbuhan

Model pertumbuhan penduduk dilakukan dengan menggunakan model pendugaan pertumbuhan yang terbaik yaitu model yang memiliki nilai koefisien determinan $\left(\mathrm{R}^{2}\right)$ tertinggi dan Standard Error (SE) terendah (Febdian dan Efendi 2013). Model pertumbuhan yang dianalisis adalah model linear, model kuadratik, model eksponensial dan model saturated dengan menggunakan software Statistica 7.0. Persamaan teknik pendugaan pertumbuhan disajikan pada persamaan (ii), (iii), (iv), dan (v).

b. Penyusunan arahan pengembangan ruang terbuka hijau (RTH)

Penyusunan arahan pengembangan RTH dilakukan dengan cara sintesis terhadap kondisi eksisting, kecukupan RTH, dan area yang berpotensi dan nilai tanah untuk dikembangkan menjadi RTH dengan berpedoman pada RTRW. Terdapat dua pertimbangan dalam kegiatan penyusunan rencana penggunaan lahan yang rasional yaitu keadaan penggunaan lahan sekarang (present land use) dan penggunaan lahan potensial (potential land use) (Sitorus 2014). Lahan yang berpotensi ditentukan dari data penggunaan lahan Kota Manna tahun 2018. Perencanaan pengembangan RTH diprioritaskan pada penggunaan lahan eksisting yang belum atau kurang digunakan secara ekonomis. Arahan ini merupakan bentuk pengendalian terhadap perubahan penggunaan lahan agar tidak terjadi perubahan ke arah yang tidak diinginkan, sekaligus diharapkan menjadi upaya pencegahan konversi RTH dan solusi dalam mengatasi permasalahan kurangnya luasan RTH Kota Manna.

5. Menyusun arahan pengendalian pemanfaatan ruang. Arahan pengendalian pemanfaatan ruang disusun berdasarkan kajian terhadap pelaksanaan 4 instrumen pengendalian pemanfaatan ruang selama ini oleh Instansi/ Dinas terkait, yaitu peraturan zonasi, pemberian izin, pemberian insentif dan disinsentif dan pemberian sanksi. Aturan terkait pengendalian pemanfaatan ruang diatur lebih lengkap dalam penjelasan Undang-undang No 26 Tahun 2007 tentang Penataan Ruang.

\section{HASIL DAN PEMBAHASAN}

\section{Penggunaan Lahan Eksisting Kabupaten Bengkulu Selatan Tahun 2018}

Penggunaan lahan di Kabupaten Bengkulu Selatan dapat diinterpretasi 8 (delapan) jenis penggunaan lahan, antara lain: hutan, industri, perkebunan, permukiman, sawah, lahan terbuka, tegalan, tubuh air. Peta penggunaan lahan di Kabupaten Bengkulu Selatan tahun 2018 dan luas 
masing-masing penggunaan lahan disajikan pada Gambar 2

dan Tabel 1.

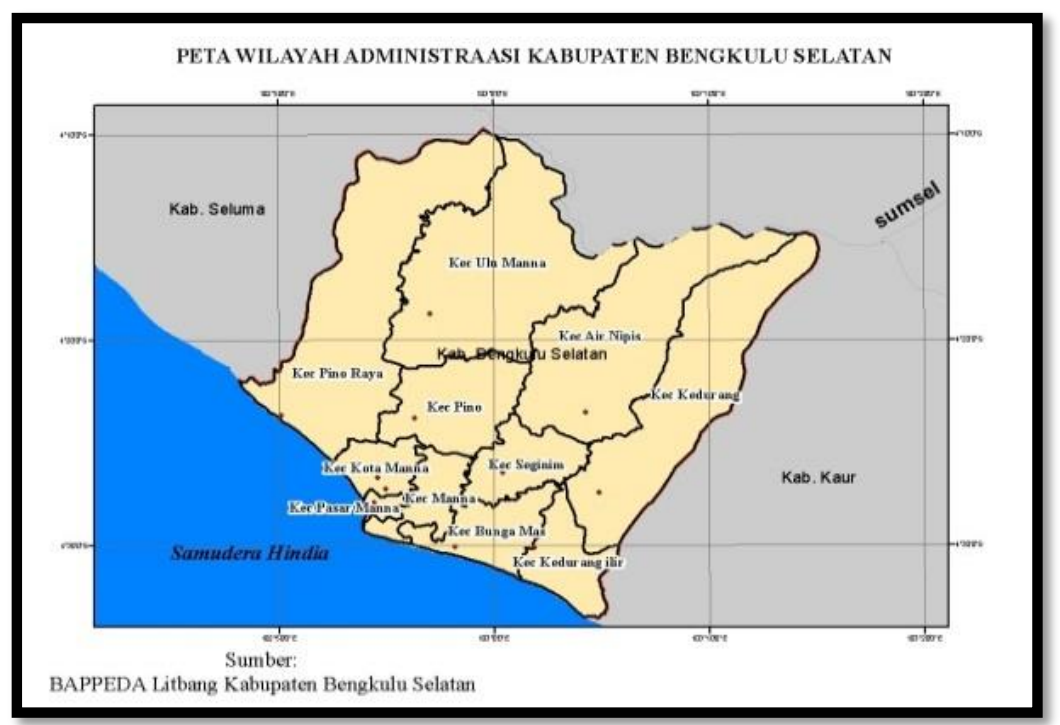

Gambar 1. Lokasi penelitian

Model Linier

Model Kuadratik

Model Eksponensial

Model Saturated

Keterangan:

Y: jumlah penduduk, $X$ : waktu ke-n, $\alpha$ : intersep, $\beta 1 \beta 2$ : konstanta (koefisien determinan), $\varepsilon$ : standart error/galat, $k s p$ : eksponensial

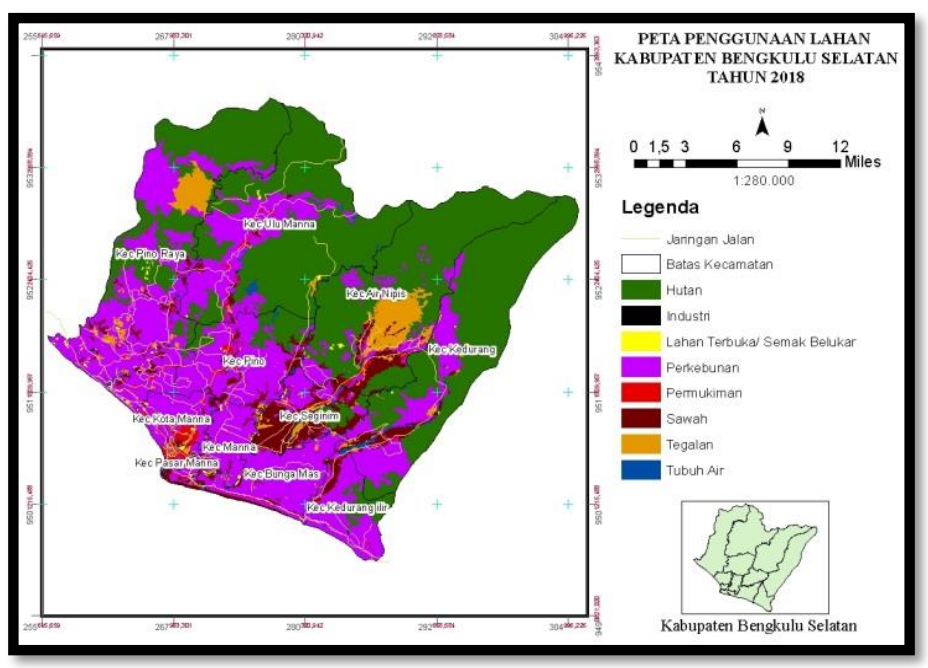

Gambar 2. Peta penggunaan lahan Kabupaten Bengkulu Selatan tahun 2018

Penggunaan lahan eksisting Kabupaten Bengkulu Selatan tahun 2018 berdasarkan interpretasi citra dan validasi lapang terdiri atas 8 jenis, yaitu hutan, industri, perkebunan, permukiman, sawah, lahan terbuka/semak belukar, tegalan, dan tubuh air. Penggunaan lahan paling luas adalah hutan dan perkebunan dengan masing-masing luas $55,861.0$ ha $(47.91 \%)$ dan $43,186.7$ ha $(37.04 \%)$.

\section{Evaluasi Keselarasan Penggunaan Lahan dengan Pola Ruang RTRW}

Indikasi selaras atau tidak selaras dilakukan dengan melihat penyimpangan yang terjadi di lapangan terhadap wilayah yang telah dialokasikan dan ditetapkan dalam pola ruang RTRW. Apabila penggunaan lahan eksisting tahun 2018 sesuai dengan pola ruangnya maka lahan tersebut disebut selaras. Sebaliknya, apabila tidak sesuai maka lahan tersebut disebut tidak selaras, dan apabila penggunaan lahan eksisting belum sesuai dengan pola ruang tetapi masih memungkinkan untuk kembali sesuai dengan pola ruang disebut transisi, misalnya penggunaan lahan saat ini berupa sawah, namun berdasarkan rencana tata ruang wilayahnya sebagai kawasan permukiman atau industri. Dengan berjalannya waktu ada kemungkinan penggunaan lahan sawah akan berubah menjadi permukiman atau industri (Tabel 2). Keselarasan Penggunaan Lahan dengan Pola Ruang RTRW Kabupaten Bengkulu Selatan disajikan pada Gambar 3 dan luasannya disajikan pada Tabel 3. 
Tabel 1. Jenis dan luas penggunaan lahan tahun 2018

\begin{tabular}{llcr}
\hline No & Penggunaan Lahan & Luas (ha) & \multicolumn{1}{c}{$\%$} \\
\hline 1 & Hutan & $55,861.0$ & 47.91 \\
2 & Industri & 56.2 & 0.05 \\
3 & Perkebunan & $43,186.7$ & 37.04 \\
4 & Permukiman & $2,617.4$ & 2.24 \\
5 & Sawah & $7,257.8$ & 6.23 \\
6 & Lahan Terbuka/Semak Belukar & 548.5 & 0.47 \\
7 & Tegalan & $4,669.3$ & 4.01 \\
8 & Tubuh Air & $2,389.8$ & 2.05 \\
\hline & Jumlah & $\mathbf{1 1 6 , 5 8 6 . 7}$ & $\mathbf{1 0 0 . 0 0}$ \\
\hline
\end{tabular}

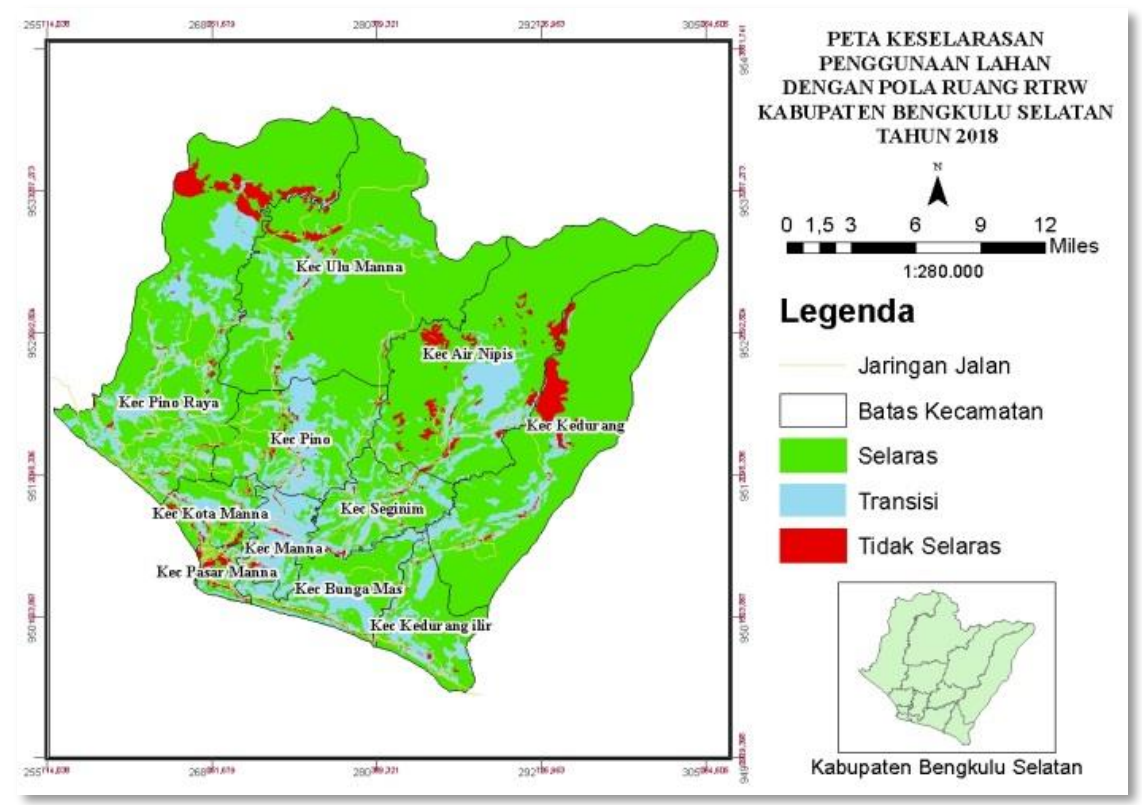

Gambar 3. Peta keselarasan penggunaan lahan dengan pola ruang RTRW

Tabel 2. Matrik logika penggunaan lahan dengan pola ruang RTRW

\begin{tabular}{|c|c|c|c|c|c|c|c|c|c|c|}
\hline \multirow{2}{*}{$\begin{array}{c}\text { PL } \\
2018\end{array}$} & \multicolumn{10}{|c|}{ Pola Ruang RTRW Kabupaten Bengkulu Selatan } \\
\hline & $\mathrm{HtL}$ & $\mathrm{HtP}$ & HPT & Ind & $\mathrm{Pk}$ & $\mathrm{Pm}$ & $\mathrm{Sw}$ & SS & $\overline{\mathrm{TT}}$ & $\overline{\mathrm{Tg}}$ \\
\hline $\mathbf{H t}$ & $\mathbf{Y}$ & $\bar{Y}$ & $\mathbf{Y}$ & $\mathbf{Y}$ & $\bar{Y}$ & $\bar{Y}$ & $\mathbf{Y}$ & $\bar{Y}$ & $\bar{Y}$ & $\bar{Y}$ \\
\hline Ind & $\mathbf{X}$ & $\overline{\mathbf{X}}$ & $\overline{\mathbf{X}}$ & $\overline{\mathbf{Y}}$ & $\bar{X}$ & $\bar{X}$ & $\bar{X}$ & $\bar{X}$ & $\bar{X}$ & $\bar{X}$ \\
\hline $\mathbf{P k}$ & $\mathbf{X}$ & $\mathbf{T}$ & $\mathbf{T}$ & $\mathbf{T}$ & $\mathbf{Y}$ & $\mathbf{T}$ & $\mathbf{T}$ & $\mathbf{T}$ & $\mathbf{Y}$ & $\mathbf{T}$ \\
\hline $\mathbf{P m}$ & $\mathbf{X}$ & $\bar{X}$ & $\mathbf{X}$ & $\mathbf{X}$ & $\bar{X}$ & $\bar{Y}$ & $\mathbf{X}$ & $\mathbf{X}$ & $\mathbf{X}$ & $\mathbf{X}$ \\
\hline Sw & $\mathbf{X}$ & $\mathbf{T}$ & $\mathbf{T}$ & $\mathbf{T}$ & $\mathbf{T}$ & $\mathbf{T}$ & $\mathbf{Y}$ & $\mathbf{T}$ & $\mathbf{T}$ & $\mathbf{T}$ \\
\hline $\begin{array}{l}\text { LT } \\
\end{array}$ & $\mathbf{Y}$ & $\mathbf{Y}$ & $\mathbf{Y}$ & $\bar{Y}$ & $\mathbf{Y}$ & $\mathbf{Y}$ & $\bar{Y}$ & $\mathbf{Y}$ & $\mathbf{Y}$ & $\mathbf{Y}$ \\
\hline$\overline{T g}$ & $\bar{X}$ & $\bar{T}$ & $\mathbf{T}$ & $\mathbf{T}$ & $\mathbf{T}$ & $\mathbf{T}$ & $\bar{T}$ & $\mathbf{T}$ & $\mathbf{T}$ & $\bar{Y}$ \\
\hline TA & $\bar{Y}$ & $\bar{Y}$ & $\bar{Y}$ & $\bar{Y}$ & $\bar{Y}$ & $\mathbf{Y}$ & $\bar{Y}$ & $\bar{Y}$ & $\bar{Y}$ & $\bar{Y}$ \\
\hline
\end{tabular}

Sumber: Listiawan (2010)

Keterangan: $\quad \mathrm{Y}=$ Selaras, $\mathrm{X}=$ Tidak Selaras, $\mathrm{T}=$ Transisi

$\mathrm{PL}=$ Penggunaan Lahan, Ht=Hutan, HtL=Hutan Lindung, Htp=Hutan Produksi, HPT=Hutan Produksi Terbatas,

Ind=Industri, $\mathrm{Pk}=$ Perkebunan, $\mathrm{Pm}=$ Permukiman, $\mathrm{Sw}=$ Sawah, $\mathrm{LK}=$ Lahan Terbuka atau Semak Belukar, $\mathrm{Tg}=$ Tegalan, $\mathrm{TA}=$ Tubuh Air

Tabel 3. Keselarasan penggunaan lahan dengan pola ruang RTRW

\begin{tabular}{lrc}
\hline Penggunaan Lahan & Luas (ha) & \% \\
\hline Selaras & $84,823.7$ & 73 \\
Transisi & $27,115.0$ & 23 \\
Tidak Selaras & $4,648.0$ & 4 \\
\hline Jumlah & $\mathbf{1 1 6 , 5 8 6 . 7}$ & $\mathbf{1 0 0}$ \\
\hline
\end{tabular}

Hasil analisis menunjukkan penggunaan lahan yang selaras seluas $84,823.7$ ha (73\%), tidak selaras seluas 4,648.0 ha (4\%), dan kawasan transisi seluas 27,115.0 ha (23\%). Daerah yang selaras masih jauh lebih luas dibandingkan dengan daerah yang tidak selaras. Meskipun demikian, penggunaan lahan yang tidak selaras merupakan hal yang perlu diperhatikan karena semakin penggunaan lahan tidak selaras dengan pola ruang kemungkinan akan menyebabkan kerusakan dan ketidakseimbangan pemanfaatan sumberdaya di masa yang akan datang. Hasil wawancara lapang dengan stakeholder pemerintah dan masyarakat menyimpulkan bahwa terjadinya ketidakselarasan penggunaan lahan dengan pola ruang RTRW Kabupaten Bengkulu Selatan adalah disebabkan 
pengetahuan masyarakat yang masih rendah mengenai RTRW, tidak ada penerapan sanksi kepada setiap pelanggaran penggunaan lahan dan belum ada sosialisasi tentang kebijakan pola ruang RTRW yang berlaku saat ini kepada masyarakat.

Penggunaan lahan yang selaras dengan pola ruang disarankan penggunaan lahannya dilanjutkan kedepannya. Penggunaan lahan yang tidak selaras dan bersifat permanen sebaiknya diakomodasikan dalam revisi penyempurnaan RTRW Kabupaten Bengkulu Selatan. Hal ini terjadi pada pola ruang yang peruntukannya untuk perkebunan atau tegalan tetapi di lapangan penggunaan lahannya sudah merupakan industri atau pemukiman, sehingga tidak memungkinkan lagi untuk diselaraskan kembali dengan pola ruang. Penggunaan lahan yang tidak selaras dengan pola ruang disarankan pengembangan lebih lanjut untuk dihentikan. Penggunaan lahan yang masih bersifat transisi adalah penggunaan lahan yang belum permanen dan masih bisa kembali dan selaras dengan pola ruang RTRW. Oleh sebab itu, pembangunan pada kawasan dengan penggunaan lahan transisi disarankan untuk dialokasikan dan dimanfaatkan sesuai dengan arahan pola ruang RTRW.

\section{Kecukupan Ruang Terbuka Hijau di Kabupaten Bengkulu Selatan}

Jenis dan Penyebaran RTH Kota Manna tahun 2018 dan kebutuhan dan kecukupan RTH Kota Manna berdasarkan luas wilayah disajikan pada Gambar 4 dan Tabel 4. Berdasarkan hasil identifikasi terdapat 13 jenis $\mathrm{RTH}$, diantaranya yang paling luas area perkebunan.

Berdasarkan Tabel 4 dapat diketahui bahwa luasan RTH eksisting secara keseluruhan sudah dapat memenuhi kebutuhan RTH sebesar 30\%, meskipun luasan tersebut tidak sesuai dengan proporsi RTH publik $20 \%$ dan RTH privat $10 \%$. RTH publik eksisting di Kota Manna belum tercukupi dengan luas 575.5 ha (19.2\%) dan masih kurang 23.2 ha $(0.8 \%)$ untuk mencapai 598.8 ha $(20 \%)$. Sementara itu, RTH privat sudah tercukupi yaitu seluas 2,006.5 ha. Luas ini lebih 1,707.1 ha dari kebutuhan yang luasnya hanya 299.3 ha $(10 \%)$.

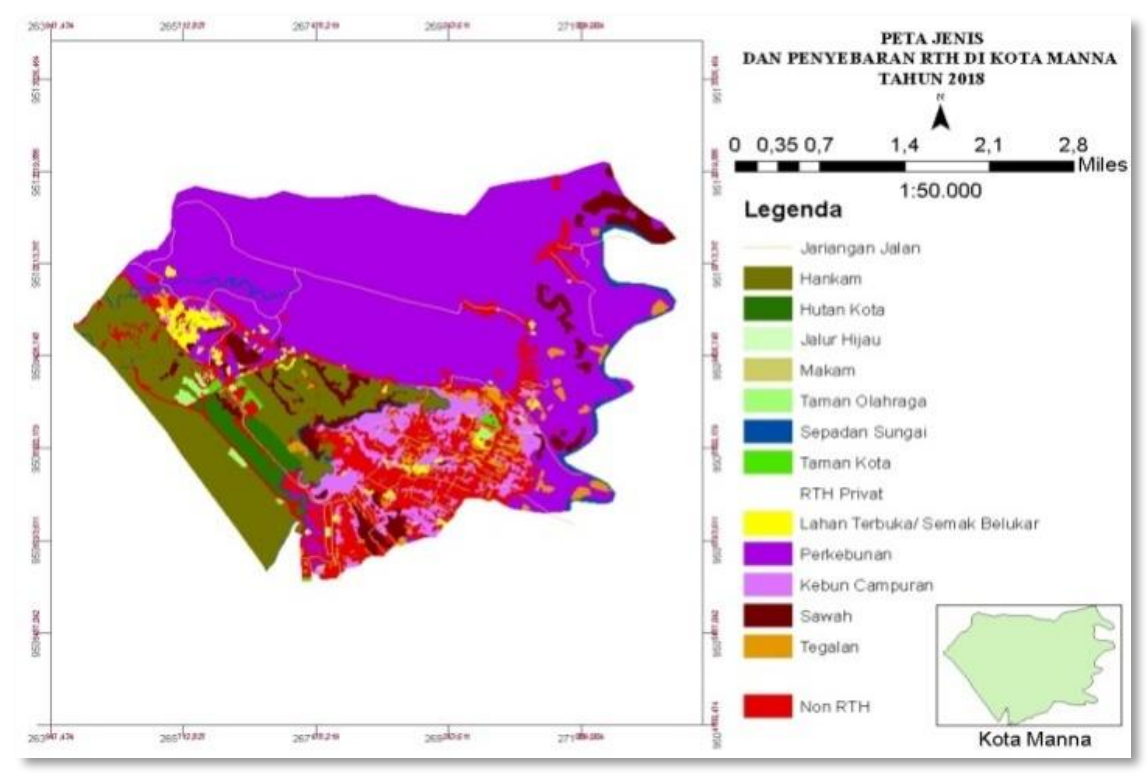

Gambar 4. Jenis dan penyebaran RTH Kota Manna

Tabel 4. Kebutuhan dan kecukupan RTH Kota Manna, Kabupaten Bengkulu Selatan

\begin{tabular}{lcccccccr}
\hline \multirow{2}{*}{ Lokasi Penelitian } & \multirow{2}{*}{$\begin{array}{c}\text { Luas } \\
\text { (ha) }\end{array}$} & \multicolumn{2}{c}{ Kebutuhan RTH } & \multicolumn{2}{c}{$\begin{array}{c}\text { RTH } \\
\text { Eksisting }\end{array}$} & \multicolumn{2}{c}{ Kecukupan RTH } \\
\cline { 3 - 9 } & & $\begin{array}{c}\text { Publik } \\
\text { (ha) }\end{array}$ & $\begin{array}{c}\text { Privat } \\
\text { (ha) }\end{array}$ & $\begin{array}{c}\text { Publik } \\
\text { (ha) }\end{array}$ & $\begin{array}{c}\text { Privat } \\
\text { (ha) }\end{array}$ & $\begin{array}{c}\text { Publik } \\
\text { (ha) }\end{array}$ & $\begin{array}{c}\text { Privat } \\
\text { (ha) }\end{array}$ \\
\hline Kota Manna & $\mathbf{2 , 9 9 3 . 8}$ & 598.8 & 299.3 & 575.5 & $2,006.5$ & $\mathbf{- 2 3 . 2}$ & $\mathbf{+ 1 , 7 0 7 . 1}$ \\
\hline Persentase (\%) & $\mathbf{1 0 0 . 0}$ & $\mathbf{2 0 . 0}$ & $\mathbf{1 0 . 0}$ & $\mathbf{1 9 . 2}$ & $\mathbf{6 7 . 0}$ & $\mathbf{- 0 . 8}$ & $\mathbf{+ 5 7 . 0}$ \\
\hline
\end{tabular}

Keterangan: Tanda (-) minus menunjukkan luas RTH eksisting berdasarkan kebutuhan belum tercapai atau masih kurang; (+) plus menunjukkan kelebihan luas RTH eksisting dari yang dibutuhkan

Tabel 5. Kebutuhan dan kecukupan RTH Kota Manna berdasarkan jumlah penduduk

\begin{tabular}{|c|c|c|c|c|c|c|c|c|}
\hline \multirow[b]{2}{*}{ Kecamatan } & \multirow[b]{2}{*}{ Tahun } & \multirow{2}{*}{$\begin{array}{c}\text { Jumlah } \\
\text { Penduduk }\end{array}$} & \multicolumn{2}{|c|}{ Kebutuhan RTH } & \multicolumn{2}{|c|}{ Luas RTH Eksisting* } & \multicolumn{2}{|c|}{ Kecukupan RTH } \\
\hline & & & $\begin{array}{c}\text { Publik } \\
\text { (ha) }\end{array}$ & Privat (ha) & Publik (ha) & Privat (ha) & Publik (ha) & Privat (ha) \\
\hline \multirow{4}{*}{ Kota Manna } & 2018 & 33,352 & 44.5 & 22.2 & 575.5 & $2,006.5$ & 531.0 & $1,984.3$ \\
\hline & 2022 & 37,712 & 50.3 & 25.1 & 575.5 & $2,006.5$ & 525.2 & $1,981.4$ \\
\hline & 2026 & 42,601 & 56.8 & 28.4 & 575.5 & $2,006.5$ & 518.7 & $1,978.1$ \\
\hline & 2031 & 49,456 & 65.9 & 33.0 & 575.5 & $2,006.5$ & 509.6 & $1,973.5$ \\
\hline
\end{tabular}

Keterangan: (*) ketersediaan RTH pada tahun 2022, 2026, dan 2031 menggunakan ketersediaan RTH tahun 2018 karena belum diketahui luasan RTH pada ketiga tahun tersebut. 
Hasil wawancara dengan stakeholders yang terdiri dari unsur pemerintah seperti Dinas PUPR, BAPPEDA Litbang, DLHK, BPN, Dinas Ketahanan Pangan, Pemerintah Daerah, dan masyarakat baik terbuka maupun tertutup menyimpulkan bahwa belum adanya data yang valid terkait ketersediaan $\mathrm{RTH}$, belum adanya rencana detail tata ruang (RDTR) dan peraturan daerah (PERDA) tentang RTH, alokasi anggaran yang sangat sedikit untuk pengembangan $\mathrm{RTH}$, ketidaktahuan masyarakat akan kebutuhan RTH, dan pihak developer yang belum mengalokasikan RTH di setiap kawasan perumahan yang ada. Data kebutuhan dan kecukupan RTH berdasarkan proyeksi jumlah penduduk disajikan pada Tabel 5.

Tabel 5 menunjukkan bahwa kebutuhan RTH berdasarkan jumlah penduduk pada tahun 2018 adalah 66.7 ha (penjumlahan dari RTH publik 44.5 ha dan RTH privat 22.2 ha). Peningkatan luas kebutuhan RTH disebabkan karena pertumbuhan penduduk. Apabila luas RTH pada tahun 2022, 2026 dan 2031 diasumsikan sama dengan luas RTH eksisting tahun 2018, maka RTH yang sudah ada sudah mencukupi kebutuhan RTH.

\section{Arahan Pengembangan Ruang Terbuka Hijau di Kota Manna}

Perencanaan penggunaan lahan merupakan hal yang penting untuk menggunakan sumberdaya lahan secara intensif dan efisien secara berkesinambungan (Sitorus et al. 2012). Dua pertimbangan dalam penyusunan rencana penggunaan lahan yang rasional yaitu keadaan penggunaan lahan sekarang (present land use) dan penggunaan lahan potensial (potential land use) (Sitorus et al. 2015). Lahan berpotensi diperoleh dari penggunaan lahan eksisting. Penjabaran lahan yang berpotensi ditampilkan pada Tabel 6.

Tabel 6. Penjabaran lahan yang berpotensi untuk pengembangan RTH

\begin{tabular}{|c|c|c|}
\hline Prioritas & Penggunaan Lahan & $\begin{array}{c}\text { Luas } \\
\text { (ha) }\end{array}$ \\
\hline 1 & $\begin{array}{l}\text { Lahan Terbuka/ Semak B } \\
\text { Rerumputan }\end{array}$ & 38.6 \\
\hline 2 & Tegalan/ Ladang, Kebun Campuran & 226.7 \\
\hline \multicolumn{2}{|c|}{ Luas Keseluruhan (ha) } & 275.1 \\
\hline \multicolumn{2}{|c|}{ Kekurangan RTH (ha) } & 23.2 \\
\hline
\end{tabular}

Perencanaan pengembangan RTH diprioritaskan pada penggunaan lahan yang belum atau kurang digunakan secara ekonomis yang teridentifikasi sebagai lahan prioritas 1 (lahan terbuka dan semak belukar) dan lahan prioritas 2 (tegalan/ladang dan kebun campuran). Lahan prioritas 1 lebih diutamakan dibandingkan lahan prioritas 2 . Kenyataan menunjukkan kekurangan RTH publik hanya 23.2 ha, sehingga dapat dicukupi dengan menggunakan lahan prioritas 1 yaitu lahan terbuka/semak belukar/rerumputan yang luasnya sebesar 38.6 ha.

\section{Arahan Pengendalian Pemanfaatan Pola Ruang}

Pola pemanfaatan ruang wilayah menunjukkan bentuk hubungan antar berbagai aspek sumberdaya manusia, sumberdaya alam, sumberdaya buatan, sosialbudaya, ekonomi, teknologi, informasi, administrasi, pertahanan keamanan, fungsi lindung, budidaya dan estetika lingkungan, dimensi ruang dan waktu yang dalam kesatuan secara utuh menyeluruh serta berkualitas membentuk tata ruang. Pola pemanfaatan ruang wilayah meliputi arahan pengelolaan kawasan lindung, arahan pengelolaan kawasan budidaya, kawasan perkotaan dan perdesaan serta kawasan prioritas (Rustiadi et al. 2011). Berdasarkan hasil analisis keselarasan penggunaan lahan dengan pola ruang RTRW Kabupaten Bengkulu Selatan diketahui bahwa ketidakselarasan terjadi disebabkan oleh pengetahuan masyarakat tentang RTRW Kabupaten Bengkulu Selatan yang rendah, tidak adanya penerapan sanksi atas penyimpangan penggunaan lahan, dan belum adanya sosialisasi tentang alokasi penggunaan lahan RTRW Kabupaten Bengkulu Selatan.

Arahan pengendalian pemanfaatan ruang disusun berdasarkan kegiatan pengendalian pemanfaatan ruang yang sudah dilaksanakan pemerintah hingga saat ini. Dalam melakukan pengendalian pemanfaatan ruang terdapat empat instrumen yang dapat digunakan untuk menjaga kesesuaian dalam pemanfaatan ruang. Adapun keempat instrumen tersebut adalah peraturan zonasi, pemberian izin, insentif dan disinsentif, serta sanksi.

Peraturan zonasi merupakan hal paling dasar dalam melakukan pengendalian pemanfaatan ruang. Kabupaten Bengkulu Selatan saat ini masih belum memiliki zonasi terkait alokasi penggunaan lahan sehingga diduga merupakan salah satu penyebab terjadinya penggunaan lahan yang transisi dan penggunaan lahan yang tidak selaras dengan pola ruang RTRW. Saat ini, pemerintah Kabupaten Bengkulu Selatan masih dalam proses penyusunan Rencana Detail Tata Ruang, itupun hanya untuk dua kecamatan saja yaitu Kecamatan Kota Manna dan Kecamatan Pasar Manna. Oleh sebab itu, pemerintah Kabupaten Bengkulu Selatan perlu segera membuat peraturan Zonasi dengan menetapkan zona-zona sesuai dengan arahan alokasi pemanfaatan ruang.

Pemberian izin terhadap penggunaan lahan sangat penting untuk menjaga keselarasannya dengan pola ruang RTRW. Pemberian izin harus disesuaikan dengan arahan alokasi pemanfaatan ruang RTRW Kabupaten Bengkulu Selatan. Sehubungan dengan pembangunan perumahan dan lahan terbangun lainnya yang banyak dilakukan di Kecamatan Kota Manna dan Kecamatan Pasar Manna, pemberian izin mendirikan bangunan (IMB) belum sepenuhnya mengacu pada arahanpemanfaatan ruang RTRW. Oleh sebab itu, pemberian ijin mendirikan bangunan perlu lebih diperketat sesuai dengan arahan alokasi pemanfaatan ruang. Hal yang sama juga berlaku untuk kecamatan lainnya di Kabupaten Bengkulu Selatan.

Pengendalian pemanfaatan ruang juga dapat dilakukan dengan cara memberikan imbalan insentif atau disinsentif terhadap pelaksanaan kegiatan pemanfaatan ruang. Pemberian insentif dapat berupa keringanan pajak dan kompensasi terhadap kegiatan yang sejalan dengan tata ruang. Pemberian disinsentif dapat berupa pengenaan pajak tinggi, pembatasan akses dalam penyediaan infrastruktur, penalti untuk aktivitas pemanfaatan ruang yang tidak sejalan dengan tata ruang. Mengingat instrumen ini belum dilaksanakan, maka instrumen pengendalian insentif dan disinsentif dalam rangka pengendalian pemanfaatan ruang perlu segera dilaksanakan oleh pemerintah Kabupaten Bengkulu Selatan supaya penggunaan lahan selaras dengan pola ruang RTRW. Untuk itu, perlu segera disusun pedoman operasional pelaksanaan pemberian insentif dan 
disinsentif.

Penerapan sanksi sebagai salah satu instrumen pengendalian pemanfaatan ruang perlu diberikan untuk setiap aktivitas pemanfaatan ruang yang tidak selaras dengan tata ruang, pelanggaran peraturan zonasi, pemanfaatan ruang yang tidak memiliki izin, pemanfatan ruang yang menghalangi akses terhadap kepentingan umum dan pemanfaatan ruang dengan izin yang diperoleh dengan proses yang tidak sebagaimana mestinya. Pemberian sanksi dapat berupa peringatan tertulis, penghentian sementara aktivitas, penutupan lokasi, pencabutan izin, pembongkaran bangunan, pemulihan fungsi ruang dan denda administratif. Pelanggaran terhadap peraturan daerah dikenakan sanksi pidana yang merujuk pada peraturan dan perundangundangan yang berlaku. Ketidakselarasan penggunaan lahan dengan pola ruang di Kabupaten Bengkulu Selatan salah satunya disebabkan oleh belum dilaksanakan penerapan sanksi terhadap setiap penyimpangan penggunaan lahan. Oleh sebab itu, pemerintah Kabupaten Bengkulu Selatan perlu dengan tegas dalam penerapan sanksi kepada pelanggar pemanfaatan ruang untuk memberikan efek jera kepada pelanggar dan mencegah penyimpangan penggunaan lahan lebih lanjut.

Berdasarkan hasil penelitian yang telah dilakukan, meskipun tingkat penyimpangan penggunaan lahan masih berada pada kategori rendah, akan tetapi tetap diperlukan upaya monitoring dan evaluasi secara berkala untuk meningkatkan keselarasan penggunaan lahan dengan pola ruang RTRW. Kerjasama seluruh pihak, baik itu pemerintah, masyarakat, swasta serta stakeholders lainnya perlu lebih ditingkatkan dalam upaya me-monitor penggunaan lahan untuk mencegah terjadinya ketidakselarasan atau penyimpangan dalam pemanfaatan ruang wilayah.

\section{SIMPULAN}

Jenis penggunaan lahan di Kabupaten Bengkulu Selatan terdiri atas hutan dengan luas sebesar 55,861.0 ha $(47.91 \%)$, industri seluas 56.2 ha $(0.05 \%)$, permukiman seluas $2,617.4$ ha $(2.24 \%)$, perkebunan seluas $43,186.7$ ha (37.04), sawah seluas $7,257.8$ ha $(6.23 \%)$, lahan terbuka/semak belukar seluas 548.5 ha $(0.47 \%)$, tegalan seluas $4,669.3$ ha $(4.01 \%)$, dan tubuh air seluas $2,389.8$ ha $(2.05 \%)$.

Sebagian besar penggunaan lahan eksisting sudah selaras dengan rencana pola ruang RTRW yaitu sebesar $84,823.7$ ha $(73 \%)$. Penggunaan lahan yang berada pada keadaan transisi sebesar 27,115.0ha (23\%), dan penggunaan lahan yang tidak selaras sebesar 4,648.0ha (4\%). Luas RTH publik eksisting Kota Manna masih kurang berdasarkan luas wilayah (-23.2 ha), tetapi sudah melebihi kebutuhan berdasarkan jumlah penduduk $(2,515.3 \mathrm{ha})$.

Luas RTH privat sudah melebihi kebutuhannya, baik berdasarkan luas wilayah maupun berdasarkan jumlah penduduk.

Arahan pengembangan RTH publik Kota Manna dilakukan pada lahan prioritas 1 yaitu lahan terbuka/semak belukar/rerumputan dengan luas 38.6 ha. Luas lahan prioritas 1 sudah mencukupi untuk pengembangan RTH publik untuk memenuhi kebutuhan RTH berdasarkan luas wilayah.

Arahan pengendalian pemanfaatan ruang dilakukan dengan empat instrumen, yaitu peraturan zonasi harus segera dibuat untuk menetapkan zona-zona alokasi ruang, pemberian izin harus lebih diperketat sesuai dengan arahan alokasi ruang, melaksanakan pengendalian berupa pemberian insentif dan disinsentif dengan membuat pedoman operasional dalam pelaksanaannya, serta penerapan sanksi kepada setiap pelanggar untuk menimbulkan efek jera.

\section{DAFTAR PUSTAKA}

[BPS] Badan Pusat Statistik Kabupaten Bengkulu Selatan. 2017. Kabupaten Bengkulu Selatan dalam Angka. BPS Kabupaten Bengkulu Selatan, Manna.

Febdian, L. dan Efendi. 2013. Menentukan model pertumbuhan penduduk Provinsi Sumatera Barat. Jurnal Matematika Universitas Andalas, 2(4):5458.

[Kementerian PU] Kementerian Pekerjaan Umum. 2008. Peraturan Menteri Pekerjaan Umum No 5/PRT/M/2008 Tahun 2008 tentang Pedoman Penyediaan dan Pemanfaatan RTH di Kawasan Perkotaan. Kementerian Pekerjaan Umum, Jakarta.

Listiawan, T. 2010. Hubungan antara Kelas Jalan dengan Kecenderungan Inkonsistensi Pemanfaatan Ruang di Kota Bogor Tahun 2003 dan Tahun 2007. [Skripsi]. Institut Pertanian Bogor, Bogor.

Pemerintah Republik Indonesia. 2007. Undang - Undang No 26 Tahun 2007 tentang Penataan Ruang. Pemerintah Republik Indonesia, Jakarta.

Putra, E.H. 2012. Analisis Kebutuhan Ruang Terbukaa Hijau Berdasarkan Pendekatann Kebutuhan Oksigen Menggunakan Citra Satelit EO-1 ALI (Earth Observer -1 Advanced Land Imager) di Kota Manado. Info BPK Manado, 2(1):41-45.

Putri, P. dan A.F.M. Zain. 2010. Analisis Spasial dan Temporal Perubahan Luas Ruang Terbuka Hijau di Kota Bandung. Jurnal Lanskap Indonesia, 2(2):115-121.

Rijal, S. 2008. Kebutuhan Ruang Terbuka Hijau Di Makasar. Jurnal Hutan Masyarakat, 3(1):65-77.

Rustiadi, E., S. Saefulhakim dan D.R. Panuju. 2011. Perencanaan Pengembangan Wilayah. Edisi Ketiga. Crestpent Press dan Yayasan Obor Indonesia, Jakarta.

Senanayake, I.P., W.D.D.P. Welivitiya and P.M. Nadeeka. 2013. Urban green spaces analysis for development planning in Colombo, Sri Lanka, Utilizing THEOS satellite imagery-A remote sensing and GIS approach. Urban Forestry and Urban Greening, 12:307-314.

Sitorus, S.R.P., S.I.D. Patria dan D.R. Panuju. 2012. Analisis Perubahan PenggunaanLahan Ruang Terbuka Hijaudi Jakarta Timur.Jurnal lanskap Indonesia, 4(2):29-37.

Sitorus, S.R.P., M. Ashri dan D.R. Panuju. 2013. Analisis Ketersediaan Ruang Terbuka Hijau dan Tingkat 
Perkembangan Wilayah di Kota Cimahi, Provinsi Jawa Barat. Jurnal Tanah dan Lingkungan, 14(1):21-28.

Sitorus, S.R.P. 2014. Pengembangan Sumberdaya Lahan Berkelanjutan. Departemen Ilmu Tanah dan Sumberdaya Lahan, Fakultas Pertanian, Institut Pertanian Bogor, Bogor.

Sitorus, S.R.P., A. Purnamasari dan S.P. Mulya. 2015. Analisis Keterkaitan PenggunaanLahan, Rencana Pola Ruang dan Hirarki Wilayah di Kota Cilegon. Dalam: Putra IGPA, Sudharsana IMG, Sukamara IN (Editor). In Prosiding Seminar Nasional Tata Ruang dan Space \#2. Memastikan Penataan Ruang Pembangunan yang Berkelanjutan: Kearifan Lokal dan Budaya Dunia dalam Penataan Ruang; Bali. 15 Oktober 2015; Program Studi Perencanaan Wilayah dan Kota, Fakultas Teknik, Universitas Hindu Indonesia, Denpasar, Bali. Hal. 501-508. Denpasar

Suwarli, S.R.P. Sitorus, Widiatmaka, E.I.K. Putri dan Kholil. 2012. Dinamika Perubahan Penggunaan Lahan dan Strategi Ruang Terbuka Hijau (RTH) Berdasarkan Alokasi Anggaran Lingkungan Daerah (Studi Kasus Kota Bekasi). Jurnal Forum Pascasarjana, 35(1):37-52. 